\title{
A case of an unusual Foreign Body of Rectum: Presentation and Management
}

\author{
Dr. Thimmaraj Nayaka N S ${ }^{1}$, Dr. Rajkumar Gupta ${ }^{2}$ \\ ${ }^{12}$ (Department of G I Surgery, Santokba Durlabji Memorial Hospital, Jaipur, India)
}

\begin{abstract}
We present a case report of an unusual large foreign body $(F B)$ in Rectum which was retrieved successfully by trans anal route. Our patient presented with retained rectal foreign body following an assault while travelling in train, he was made unconscious and was later found in a pool of blood with per rectal oozing. Patient was then evaluated and trans anal retrieval of $F B$ was carried out successfully.
\end{abstract}

Key words: Foreign Body, Klismaphilia, Management, Rectum,Trans anal retrieval

\section{Introduction}

Rectal FB's are not uncommon in emergency departments worldwide and FB's of various sizes and shapes have been reported in literature [1]. FB's seen in anorectal region, however, have shown to surprise radiologists and surgeons from time to time. Majority of objects are introduced through anus; however, sometimes though rarely a swallowed FB may be seen to have reached rectum and be a cause for trouble. Rectal FB's are known for potential complications and present as a challenge to clinical diagnosis and management. The management emphasis is on trans anal retrieval and ruling out of the rectal and colonic perforation.

\section{Case Report}

A 28 years old male patient came to the surgical emergency with complaints of pain lower abdomen, difficulty in passing stools and bleeding per rectum. On further coaxing him he revealed the history of assault 10 days earlier while travelling in a train he was made unconscious and was later found in pool of blood with per rectal oozing. No similar history in past or any psychiatric illness noted. Vital signs were normal. Abdomen was soft. FB was not felt per abdomen. Per rectal examination was postponed (to avoid injury if sharp objects encountered).

With high suspicion of sexual assault, CECT of lower abdomen with IV, oral and rectal contrast was requested and it showed dilated recto sigmoid colon with a large foreign body i.e. an air filled bottle within it. There was mild concentric mural thickening of the affected colon. The rectal contrast was seen to pass in the colon proximal to FB. Proximal bowel loops appeared normal. No free air or fluid was seen intraperitoneally (fig.1).

After valid consent, patient was shifted to operating room for manual extraction of FB under general anesthesia. With patient in lithotomy position, anal dilatation was done and an attempt to retrieve FB was made with help of retractors, graspers and snares. Initial attempt at holding the base of bottle was difficult and slippery due to mucus coating over it. And any manipulation of bottle upside down was practically impossible because of its size. With repeated attempts and gentle pressure over abdomen, bottle was retrieved by gentle traction trans anally (fig.2). Post removal per rectal examination and sigmoidoscopy did not revealed any colorectal injury except for some minor anal tears. Post removal recovery was uneventful without any perianal infection or anal incontinence.

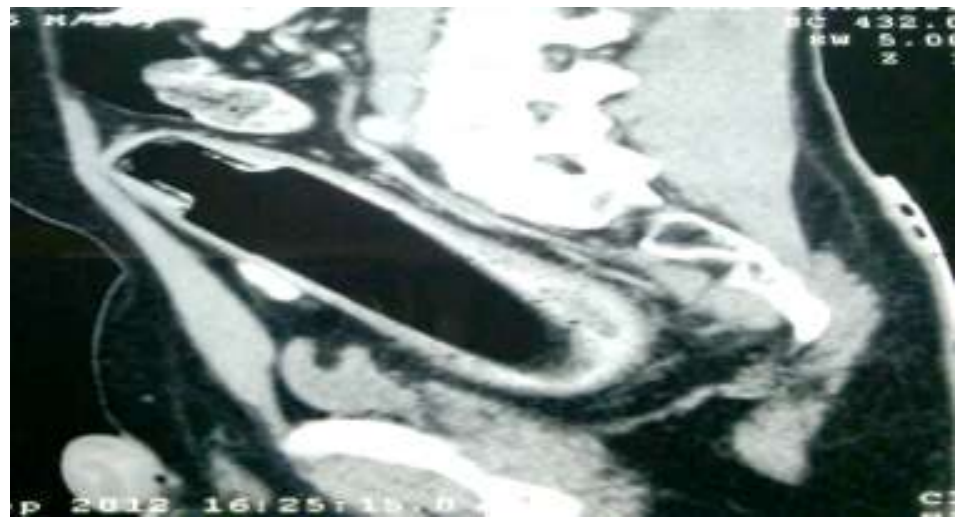

Fig. 1. CECT of Abdomen and Pelvis showing high lying Foreign Body 


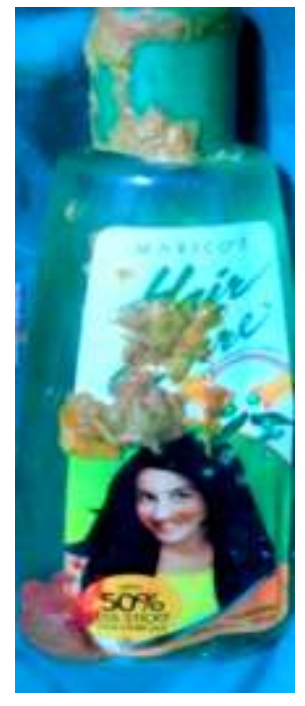

Fig. 2. Extracted FB

\section{Discussion}

Foreign bodies of rectum are known for its complications and present as a challenge in clinical diagnosis and management. The variety of objects removed from rectum defies our imagination. Incidence varies from place to place, more commonly seen in Eastern Europe and uncommon in Asia [2-4].

Males are commonly affected and are seen in all age groups, observed in twenties for anal erotism or forced introduction through anus and in the sixties mainly for prostatic massage and breaking faecal impactions.

Most such cases are seen as a result of erotic activity, wherein objects ranging from dildoes and vibrators to large objects like bulbs, glasses, beer bottles, etc. have been seen. Other causes for insertion are diagnostic or therapeutic reasons (examples would be a broken rectal thermometer and broken enema catheter tips), self treatment of anorectal disease (constipation), Klismaphilia (use of enemas for sexual gratification), drug smuggling, assault or accident. Rarely a swallowed object may reach the rectum for e.g. fish bone, swallowed tooth etc. The object length varies between 6 and $15 \mathrm{cms}$ and larger objects are more prone for complications [2].

Abdominal and rectal pains, bleeding per rectum are the common presenting symptoms. Per rectal examination is the cornerstone in the diagnosis, but it should be performed after X-ray abdomen to prevent accidental injury to the surgeon from sharp objects.

Eftaiha et al [5] classified Foreign bodies in rectum as high lying or low lying depending on its relation with rectosigmoid junction. Objects lying above rectosigmoid junction are considered high lying and are difficult to remove per-rectally even with proctosigmoidoscope.

First step in management of such cases is a thorough radiological examination of the patient. Firstly a plain $\mathrm{x}$-ray abdomen erect should be done to rule out any perforation and obstruction, most common complications of FB in rectum. It also gives us the tentative position of the object, if above the sacral curvature considered as high-lying.

A CECT will give us more detailed 3D view of the position of FB. It also helps us evaluate the complications like perforation, obstruction and impaction. It gives us detailed image of the rectal wall to rule out mucosal edema and lacerations. It helps the surgeon to have a 3D approach and makes it easy to choose the best and least invasive method of extraction.

Majority $(90 \%)$ of the cases is treated by transanal retrieval $[2,6,7]$. Hard objects are potentially traumatic and tend to migrate upwards [8]. Abdominal manipulation and stabilization helps in retrieval when the bottle is slippery. Obstetric forceps or snares are only helpful in grasping the broad and slippery base with limited success. Trans anal retrieval should always be done under direct vision [9]. Colonoscopy removal is also reported with good success [10].However, limited studies in the literature restrict the definition of the major role of colonoscopy.

Laparotomy is only required in impacted foreign body and or with perforation peritonitis. Even with laparotomy, the aim is transanal removal and closure of perforation with diversion colostomy. However, Kingsley et al. [11] proposed that laparotomy should be considered as the primary method of treatment if the patient presents with a high-lying foreign body impacted for 24 hours or longer. Postretrieval colonoscopy is mandatory to rule out colorectal injury. 


\section{Conclusion}

Rectal foreign bodies present a difficult diagnostic and management dilemma because of delayed presentation, a variety of objects, and a wide spectrum of injuries so that no single procedure for their removal can be recommended. A thorough radiological evaluation always gives an insight to the surgeon about the foreign body and its complications that are waiting inside.

\section{References}

[1] Feigelson S, Maun D, Silverberg D, Menes T. Removal of a large spherical foreign object from the rectum using an obstetric vacuum device: a case report. Am Surg 2007; 73:304-6

[2] Subbotin VM, Davidov MI, Abdrashitov RR, Rylov IuL, Sholin NV. Foreign bodies in rectum. Vestn Khir Im I I Grek. 2000; 159:91-5.

[3] Neprasova P, Treska V, Simanek V. Injury of rectum with porcelain cup (Czech) Rozhledy V Chirurgii. 2001; 80:128-30.

[4] Batho G, Szanto L. Foreign bodies in rectum at our department during last ten years. (Hungarian)Magyar Sebeszet. 2000; 53:180-2.

[5] Eftaiha M, Hambrick E, Abcarian H. Principles of management of colorectal foreign bodies. Arch Surg 1977; 112:691-5.

[6] Petrolito E, Bracchitta S, Calabrese C, Riolo G, Donati A, Pecorella G. Foreign bodies and injuries of the rectum (Italian) Minerva Chirurgica. 1989;44:867-71

[7] Kouraklis G, Miaiakos E, Dovas N, Karatzas G, Gogas J. Management of foreign bodies of the rectum: Report of 21 cases. J R Coll Edin. 1997; 42:246-7.

[8] Yaman M, Dietel M, Burul CJ, Hadar B. Foreign bodies in the rectum. Can J Surg. 1993;36:173-7

[9] Singaporewalla RM, Tan DE, Tan TK. Use of endoscopic snare to extract a large rectosigmoid foreign body with review of literature. Surg Laparosc Endosc Percutan Tech 2007; 17:145-8.

[10] Gaponov VV. Foreign bodies in the rectum and colon (Russian) Klinicheskaia Khirugiia. 1992; 2:37-40.

[11] Nehme Kingsley A, Abcarian H. Colorectal foreign bodies.Management update. Dis Colon Rectum 1985; 28:941-4. 